\title{
Universities and companies: a creative partnership in the building of sustainable cities
}

\author{
D. C. Vivas Neto, L. B. Santos \& E. A. Nascimento \\ Department of Engineering, Federal Fluminense University, Brazil
}

\begin{abstract}
The study we conducted describes a university and a company as important actors in the process of building sustainability. This article presents two experiences: the first refers to the Fluminense Federal University, through the extension activities. The second refers to the Energy Company, through the concept AMPLA of social responsibility.
\end{abstract}

Keywords: sustainable cities, university, extension programs, social responsibility.

\section{Introduction}

Since 1992, various activities have been developed such as courses, research and events. This article focuses on extension activities, since they have made a significant difference in socio-environmental problems in central, suburban, peripheral, countryside, and risky cities. Extension is defined by the Pro-Rectory Forum as an educative, cultural and scientific process in which education and research are integrated, enabling a transforming relationship between university and society [1].

Extension activities are structured according to the following thematic areas: Communication, Culture, Human Rights and Justice, Education, Environment, Health, Technology and Production, and Labor. Each thematic area develops its action under specific programmatic methods in which interdisciplinarity is stimulated, thus contributing to thematic interfaces and interactions. A key role is played by the participation of university entities involved in extension activities in the development and promotion of public policies oriented to the majority of the population, to the permanent qualification and education of managers involved in social systems, and to the availability of new methods and processes 
of production, innovation, and knowledge transfer. These initiatives broaden the access to education and help in the technological and social development of the country. Therefore, they are extremely important when dealing with the mentioned issues [1].

Despite their uncountable problems, Brazilian urban areas are currently a place for extension activities that seek solutions for the existing problems through courses and projects. It is known that such problems are structural, deriving from the urbanization model implemented in Brazil since the beginning of the $20^{\text {th }}$ century. We acknowledge that solutions lie beyond technical activities performed by an external agent, be it a university, a company or an ONG. Public policies are necessary in order to overcome these problems, counting on cities to play a social role. This social role consists of the democratization of territories, as well as productive and cultural areas, thus providing full access to the various functions of the city. Therefore, the actions presented in this article are extremely important, as will be shown in other articles.

\section{University and extension programs: strategy of sustainability building}

University extension programs officially appeared in Brazil in 1931, after the Decree-Law 19.851 that established the Brazilian University Statute. In 1961, the Law of Guidelines and Bases for National Education (LDB) gave the extension activities an assistentialist feature, transforming them into a vehicle for the transmission of knowledge produced only within the academic research context.

In 1968, the University Reform was introduced by the Law 5.540 that made Extension mandatory for all higher education institutions. Courses and services oriented to society were implemented, but under an assistentialist and authoritarian perspective. It was believed that the university was the one to transfer knowledge to society, thus it was not a two-way street.

In the 80s, a new stage in the consolidation of Brazilian university extension happened. The strengthening of civil society enabled the debate on the university role, and consequently on the role of Extension. As a result, the university approached the Brazilian social reality, mainly working along with the new urban social movements related to health and housing issues. A new link between university and society was established, thus creating a new paradigm.

In 1987, the creation of the Extension Pro-Rectory Forum of Public Universities consolidated this new relationship between university and society. One year later, the principle of education-research-extension indissociability would be promulgated in Brazil's Federal Constitution:

“Art. 207. Universities hold didactic-scientific, administrative, and financialpatrimonial autonomy, and shall obey the principle of indissociability between education, research, and extension."

The Extension Pro-Rectory Forum of Public Universities developed the Extension National Policy based on the principle of indissociability between education, research, and extension, as well as its transforming power that promotes social interaction and interdisciplinarity. It is worth mentioning that the 
Extension Forum was part of the national mobilization in favor of the inclusion of an urban policy in the Constitution being developed at that time [2, 3].

In this way, the Extension National Plan published in November 1999, focused on some of the problems identified by society during the elaboration of the Constitution of 1988: poor housing; meager urban services and infrastructure; poor transportation system; inadequate use of the urban soil; lack of leisure sites; and degradation of ecosystems; thus failing to meet the basic needs of the population.

As a result, the following Guidelines for the University Extension were issued:

Impact and transformation: establishment of a link between the university and other sectors of society, aiming for a transforming participation oriented towards the interests and needs of the majority, as well as promoting public policies and local development;

Dialogic interaction: development of links between university and society characterized by dialogues, both-way actions, knowledge exchange, overcoming the speech of the academic hegemony, that is to say, a partnership with social movements aiming to surmount inequality and exclusion;

Interdisciplinarity: characterized by the interaction between models and complementary concepts, and between analytical materials and methodologies, searching for technical and operational consistency to structure the role of the social process elements and to conduct towards organizational, professional and personal interaction and inter-relation;

Education - Research - Extension indissociability: every extension activity must be related to the education and knowledge promotion process, considering the student the protagonist of his technical education in order to achieve the competences required for his performance as a professional and as a citizen recognizing himself as an agent whose rights and obligations must be observed, holding a transforming view and compromise over society.

These guidelines contributed to the universities assume, as an institution, their role on the solution of problems in the country, along with other sectors. There was an approach between university and members of Health, Transport and Housing Forums; movements related to gender, ethnical and environmental issues; campaigns for the valorization and protection of underprivileged people. It is important to mention that this compromise was made during a peculiar moment in the Brazilian urban scenario: peripherization through the increase in the number of poor people in cities and big metropolises. Among the 33 million poor, $35 \%$ lived in cities and $41 \%$ in the metropolises. A considerable amount of these people came from the countryside, which was strongly affected by the economic crisis of the 80 s [1-3].

\section{UFF extension program}

The Federal Fluminense University - UFF - is located in Niterói, Rio de Janeiro. It offers around XXX courses, with an average of 44,000 students divided into 
5 campuses: Niterói, Campos dos Goytacazes (PUCG), Nova Friburgo (Punf), Rio das Ostras (Puro), and Volta Redonda (PUVR).

Until the 90s, UFF had kept itself away from social issues, as well as most Brazilian universities. Through the development of education and health related actions by professors on peripheral areas, this situation started changing.

The development of the Extension National Policy helped consolidate extension at UFF through a number of activities in the cities, mainly in the countryside. Such activities are developed by professors and students, promoting not only technical education, but also social education. The students, differently from the ones who graduated in the past, have the chance to get in touch with information concerning the reality of the country, so that when graduated they can commit themselves to the transformations needed, mainly the ones related to the development of amplified and progressive sustainability.

Nowadays, part of the graduation program can be fulfilled by extension activities. It contributes to an effective participation of students in relevant national issues, e.g., urban sustainability. This issue has been covered in courses, such as Geography, Law, Economics, and more recently Civil Engineering.

According to the National Plan of Extension, the main extension activities can be performed under the following categories [3]:

a) Programs - set of medium and long term organic-institutional activities, whose rights are clear and target-oriented, articulating projects and other activities (courses, events, services, and academic production), including research and education.

b) Projects - set of continuous, process-based activities under an educative, social, cultural, scientific or technological approach. Objectives and deadlines are well defined, and are either related to a program or not.

c) Extension courses - set of coordinated pedagogical actions, which can be either theoretical or practical, in the classroom or by distance, systematically planned and organized, with minimum 8 credit hour class and an evaluation process.

d) Events - consist of public and free, or customer-specific presentation of knowledge or cultural product, scientifically and technologically developed, preserved and recognized by the university.

e) Service - transference of knowledge generated and established in the university to the society, i.e., universities are hired by third parties (community or companies).

f) Publishing and other academic products - characterized by the production and the academic products derived from extension activities, aiming for cultural, scientific or technological diffusion and spreading.

Currently, UFF develops about 559 projects divided into the areas listed in Table 1.

About $60 \%$ out of this total are related to socio-environmental issues in urban areas, contributing to the achievement of some targets established in the Constitution of 1988, City Statute, Brazilian Agenda 21, and Sustainable Cities Platform: 
Guarantee of the right to sustainable cities: defined as the right to urban soil, housing, environmental sanitation, urban infrastructure, transportation, public services, labor, and leisure;

Several extension activities at UFF focus on land regularization, mainly in peripheral cities: regularization of lands, acquisition of ownership titles. It is extremely important, given that many of these lands have not received any kind of investment from the government, once they are considered illegal and not part of the "city". Regularization allows dwellers to claim investments in sanitation, water supply, public lightning. There are two significant experiences at UFF: the first one is the project from the Architecture Faculty. It has been running for more than 10 years and has already incorporated many clandestine areas to the "legal" city. The second project is developed by the Civil Engineering Department and refers to the monitoring of risky areas. They are identified by a special piece of software, then professors and students propose preventive measures. After the landslide tragedy in Morro do Bumba, which struck its population in 2010, dwellers took advantage of studies performed by professors of these projects to make the State responsible for its omission.

Table 1: $\quad$ Extension program - source: www.proex.uff.br/2012.

\begin{tabular}{|l|c|}
\hline Area & Number of Projects \\
\hline Communication & 29 \\
\hline Culture & 42 \\
\hline Human Rights & 144 \\
\hline Education & 140 \\
\hline Environment & 27 \\
\hline Health & 142 \\
\hline Technology and Production & 20 \\
\hline Labor & 15 \\
\hline Total & 559 \\
\hline
\end{tabular}

Democratic management of cities: through the participation of the population and associations connected with the various social groups, in the formulation, execution, and follow-up to plans, programs, and projects related to urban development;

Historically, Brazilian population was kept away from decision-making processes, especially the ones related to urban management. When participation started to be guaranteed by legal instruments, it was necessary to qualify ONG members, community associations, and other segments. Extension activities contributed to the active participation of the population in the development of public policies, mainly in the Social Service, Law, and Education areas. The most relevant experiences are related to the development of the Guiding Plans and the Participatory Budgeting. 
Cooperation among governments, companies, and other sectors of society in the urbanization process aiming for the social interest;

Traditionally, Brazilian companies do not cooperate with the solution of social problems. Since the 90s, many of them have adopted the social responsibility concept, thus getting involved in project partnerships with university extension programs. Universities played a key role in this process, by offering coaching courses dedicated to the productive sector. At UFF, LATEC is one of the most significant experiences.

Planning the development of cities, the spatial distribution of the population, as well as the economic activities in the cities and territories under their influence, aiming to prevent and review distortions in urban growth and the negative effects on the environment;

One of the most outstanding experiences led by UFF has been performed in the northwest areas of the state of Rio de Janeiro, formed by countryside cities. This action resulted in the creation of the Municipal Committee of the Environment - COSEMA. This committee is composed by municipal secretariats of the environment, and is directly assisted by experts from UFF. Its foundation has positively contributed to the widespread application of the sustainability concept, and to its incorporation in the sectors of the city administration. In addition, it has given visibility to the region on the national scene, thus supporting the acquisition of financial resources. Later, the most important aspects of this project will be depicted, explaining how it has helped develop regional sustainability in an amplified and progressive way [4].

The region had its economy based on the sugar-alcohol industry, coffee planting, and cattle and was considered the most innovative and dynamic in Rio de Janeiro. However, it suffered a significant socio-economic decline caused by the state and national economic crisis in the 80s. As a result, the region presents an unsustainable scenario nowadays.

The presence of the Fluminense Federal University in the region through extension activities enabled reflection on the regional problems and the foundation of a working group arose. Throughout the National Conference of Environmental Health, held in São José de Ubá-RJ in 2009, the proposal for the creation of COSEMA was presented for plenary voting. The Committee consists of the following characteristics: composed by environment secretariats; regional scope - intermediate territorial scale between state and city; promotion of sustainable development in its various dimensions - long term public policies; direct assistance of experts from public universities and research centers [4]. The Committee performance has led the way to sustainable cities, as they:

a) Make an environmental, social, and economic commitment, which so far had either not been discussed or been just fragmentally discussed by each city, and now has adopted a systemic and holistic approach at a regional level. The most outstanding example is related to the struggle against floods in the region. Before the foundation of COSEMA the incidents were casually handled, limiting themselves to engineering interventions and without any concern towards socioenvironmental issues. Today, the agenda of meetings that deal with this subject includes the following: deforestation and the need for reforestation, the illegal 
occupation of riverbanks and the need for regional housing policy, waste disposal in rivers and the need for a policy oriented to basic sanitation, and the change in local culture through eco-citizenship programs. The incorporation of these issues by COSEMA has been made through the innovative participation of the secretariats in promoting environmental education. Environmental education was inserted in the scope of the Secretariat of Education, sharply tackling the physical, chemical, and biological aspects. COSEMA members' reflection, mainly with regard to sustainability and its dimensions, contributed to the implementation of some projects in the field of municipal management. One of these projects approaches basic education by rescuing municipal gardens, which have previously been used only for planting sites of exotic fruit saplings, but now are used as pedagogical sites to develop projects and eco-citizenship programs offered to the local community. Furthermore, besides producing exotic saplings, some gardens also grow native saplings stemming from Atlantic Forest with the purpose to use them for the reforestation of devastated areas and for being planted by rural farmers in permanent preservation areas - APP - located in their properties. Further plans are to establish the region as a production center of saplings from Atlantic Forest, once the State does not count on sufficient saplings to fulfill the planting demand [4].

b) deal with problems under the view of sustainability - data and information presented by COSEMA members in work meetings are spread in their respective city halls. Although there have been no public policies oriented towards sustainable development in the region, the previously mentioned procedure has concerned both municipal and state entities. The management of solid waste in the region can be mentioned as an example of such concern, once they had been inappropriately disposed so far. In this way, COSEMA members have participated as promoters and facilitators in the foundation process of the Northwest Landfill II [4].

UFF presence has been crucial in order to achieve a systemic approach on the local problems, an approach under the view of sustainability.

In 2012, researchers from the HIDROUFF group will join this project, thus integrating it with other initiatives. At first, a possible partnership may be established under the concept of Social Responsibility with AMPLA, a company located in Niterói. AMPLA also participates in projects developed in other cities, focusing on amplified sustainability, mainly under the socio-ecological dimension. Through the research group, company and university will come closer, culminating in more effective results of sustainability-related projects.

\section{Participation of companies in the development of sustainability: AMPLA's case study}

As well as universities, some Brazilian companies have also been contributing to overcome unsustainability in urban areas. Programs and projects have been developed by medium- and large-sized companies, aiming to overcome urban population's vulnerabilities. Indeed, these vulnerabilities have intensified since the 90s, affecting mainly children and adolescents from peripheral and risky 
cities. In this article, we will use as example a company named AMPLA, referring more specifically to the project Future AMPLA Conscience, which is developed in several cities in Rio de Janeiro, including the partnership between the Metropolitan Area and the Gênesis Environmental Education Center. The next partnership will be created with Fluminense Federal University following the guidelines established by the City Statute, which suggests partnerships among governments, companies, and other sectors of society in the urbanization process and fulfillment of social demands.

Agenda 21 presents two strategy groups for the development of sustainability: the first one is clearly economy-oriented and based on new technologies, international agreements, and environmental certifications; the second one is based on the participation of different social elements and on the concept of social responsibility.

This concept can be understood as the obligation a certain company has to participate in the overcoming process of socio-environmental problems by taking actions, as mentioned by Chiavenato:

"Social Responsibility is the commitment level of a company to participate in actions that protect and improve society's well-being as it aims to achieve its own goals.”

Social Responsibility is, therefore, the materialization of the company's commitment concerning the solution of socio-environmental problems. In Brazil, such commitment may be addressed to the urban problems, which causes the vulnerability of the population.

The commitment level of companies varies and can be summarized in six stages, considering at one extreme the companies with no social responsibility and no participation in citizenship-oriented actions, and at the other one the companies with social and entrepreneurial commitment leadership. The last ones systematically stimulate their staff participation in social development efforts and keep hold of evaluation tools that aim to improve the company's performance towards citizenship and public responsibilities. In doing so, such companies become partners and co-responsible for the development of sustainability, as mentioned below:

The practice of social responsibility is a way of conducting company's affair so that the company becomes partner and co-responsible for social development. Ethos Institute (2003).

Becoming co-responsible has been a big challenge to companies. Participation has still been demonstrated as help, but not really in the form of coresponsibility. In Brazil, business people have not taken their role as the main protagonists, but they have been playing a supporting role due to the several gaps present in legislation.

Social responsibility was first discussed in Brazil in the 60s, after the foundation of the Association of Christian Business Leaders (ADCE). According to one of the guiding principles of this association, its members should admit the social role of the company in favor of its employees and the community's wellbeing, besides supplying goods and services. 


\section{Brazilian social unsustainability and the role of companies}

The urbanization model implemented in Brazil has created unsustainable cities, mainly under the social perspective, and thus featuring a poverty scenario. In this scenario, whichever the city type is (central, suburban, peripheral, risky), children, adolescents, youths, men, and women continuously play the leading role in individual and collective resistance acts. Despite that, most of those people remain in a vulnerable situation, given that in order to overcome it the employment of citizenship-related skills is required, by attaining both material and non-material goods.

The term vulnerability has been approached under three perspectives: income - associating poverty with the lack or shortage of family or individual income, attested by the exclusion or meager inclusion in the labor market; services and urban structure - the lack or poor access of families and/or individuals to housing, health care, education, basic sanitation, electricity; skills - poverty is considered the total lack of basic skills to achieve minimum acceptable levels, i.e., poverty is not a matter of lacking of well-being but the incapacity to achieve it, that is to say the lack of the required means [5].

Such poverty status is materialized through psychological harm, lack of selfesteem, increasing demotivation for working, rupture with family and social links, accentuation of gender unbalance and racial conflicts, illness and death rate increase. This scenario results not only from the dominant standards of production, accumulation, and attainment of wealth in Brazil since the 90s, but also from the "combination and condensation of other ways of social subordination and segregation, e.g., professional profile, place of living, gender relations, socio-political positioning, inter-racial relations, inter-generation living ways” (Silva 2004, p.106).

This combination makes black people, women, children, and the elderly the most vulnerable people, and demands democratization measures of power relations and the reinforcement of citizenship.

In metropolitan areas of Rio de Janeiro unsustainability is intense, mainly in some urban spots of peripheral and risky cities.

\section{Social responsibility and sustainable development}

The importance of adopting socially responsible practices was acknowledged by Brazilian companies only in the 80s, through the partnership between the entrepreneurial sectors and the social movements. The sociologist Herbert de Souza, the so-called Betinho, launched a national campaign named Citizenship Campaign Against Poverty and For Life, counting on the participation of the Business National Movement. In the 90s, its recognition was consolidated through the participation of NGOs, specially the work developed by the IBASE with the spread of social balance and the foundation of the ETHOS Institute.

Currently, several companies have adopted this concept. As a result, five stages can be identified: 
Stage 1: the organization does not assume responsibility towards society and does not participate in the promotion of citizenship. Ethical behavior is not praised; indeed it is considered completely or almost outdated.

Stage 2: the organization recognizes the impacts caused by its products, processes, and structure, thus proposing some isolated actions aiming to minimize such impacts. Ethical behavior is occasionally praised.

Stage 3: the organization starts up the systematization of an impact evaluation process of its products, processes, and structure, thus assuming some leadership of communitarian issues. People commitment is present in social development efforts.

Stage 4: the impact evaluation process of products, processes, and structure reaches the systematization level. The organization assumes leadership of communitarian issues in several ways. People commitment in social development efforts is frequent. The organization promotes ethical development.

Stage 5: the impact evaluation process of products, processes, and structure is fully systematized, aiming to foresee public issues. The organization leads communitarian and sectorial issues. People commitment in social development efforts is systematic. Methods are implemented to evaluate and improve the organizational performance with regard to its citizenship role and to the handling of its public responsibilities.

The adoption of this concept has brought many benefits, both for companies and for the target public. According to current information from the Development Map of Rio de Janeiro, the benefits for companies have been the following: more acceptance among customers, staff motivation, attracting new talents, added value of the brand for suppliers and for the communities they belong, bigger market share, access to specific funding, and reduction in environmental and laborious risks.

Concerning the target public, a considerable improvement in life quality was observed, i.e., organizational participation contributes to overcoming vulnerability and developing sustainability mainly in city areas, no matter if they are central, suburban, peripheral, countryside, or risky cities.

\subsection{AMPLA and the concept of social responsibility}

AMPLA's Department of Responsibility is composed of several projects, but we choose the Future AMPLA Conscience project. This project was organized in 2002 to spread the importance of sustainable electricity use. The target public is composed of students from public and private schools, and the topics covered were: efficient use of electricity; ethics and citizenship; environmental preservation; importance of conscious consumer habits. In 2011, 100 schools were served, reaching a total of 9,000 students and their families.

The objective of the Future AMPLA Conscience project consists in making students an element of transformation spreading the importance of the conscious consumption of electricity and natural resources. Divided into three key moments, the project involves teachers and students aiming to introduce the 
concept and practice of conscious consumption in their day-by-day, as well as their families and neighborhood.

Teachers who are nominated by partner institutions, which in their turn are selected and nominated by the local Municipal Secretariat of Education, participate in sensitization/capacitation activities through the "PROCEL Methodology at Schools", thus enabling the introduction of the conscious consumption concept in different subjects. Ludic Workshops: instructions about the conscious consumption of electricity and activities that stimulate reflection and wide room for debate on currently essential topics, such as responsible consumption and sustainability. These topics are tackled with students from public schools in two moments after the capacitation of the teachers. In partnership with these professionals, we strengthen and update the contents covered throughout the whole school year and do bimestrial follow-ups in partner schools in order to observe challenges and achievements derived from the implementation of the Future AMPLA Conscience project. Besides the topics related to electricity, the project also tackles issues regarding ethics, citizenship, environmental preservation, and sustainability. Therefore, the whole school community benefits from the Future AMPLA Conscience project, including the partner school, which receives more than 570 books, games, and DVDs. These materials come from the "PROCEL Methodology at Schools" and are intended for systematic researches and knowledge exchange.

This project has helped place children and adolescents as the main characters of the actions required to overcome the problems present in their communities.

In 2012, the project will count on the participation of the Fluminense Federal University through extension programs, thus becoming a practice room for students of Pedagogy, Geography, and Biologic Sciences.

The project has presented two experiences that have contributed to the construction of sustainability: universities and companies. In the exposition on these experiences we can observe that they have greatly contributed to overcome many problems existing in the city. We think that these experiences need to be more explored. This is one of the aims of the Research Group on Environment, Sustainability and Social Responsibility.

The AMPLA project, the Northwest Fluminense project as well as the Ecomuseum project, which have been implemented in the municipality of Rio de Janeiro, is accompanied by researchers of HIDROUFF - an effective supporter of sustainability. It is extremely important, as Brazil prepares to host Rio +20 and the Ministry of the City has elected it as one of the most important theme for debates.

\section{References}

[1] Fórum de Pró-Reitores de Extensão Universidades Públicas Brasileiras e SESu / MEC. Plano Nacional de Extensão. Brasília, pp. 15, 2001.

[2] Fórum de Pró-Reitores de Extensão Universidades Públicas Brasileiras: Indissociabilidade do Ensino - Pesquisa - Extensão e a 
Flexibilização curricular: uma Visão da Extensão. Porto Alegre and Brasília, pp. 100, 2006.

[3] Corrêa, E. J. (ed). Fórum de Pró-Reitores de Extensão Universidades Públicas Brasileiras: Extensão Universitária: organização e sistematização, Belo Horizonte, pp. 112, 2007.

[4] Vivas Neto, D. C. and Nascimento E. A. Limits and possibilities for the promotion of sustainable development: the case of Northwest Region Fluminense. Proc. of the $5^{\text {th }}$ Sustainable Development and Planning, eds. C.A. Brebbia and E. Beriatos, WIT Press: UK, pp. 19-28, 2011.

[5] Dupas, G. Global Economy and Social Exclusion: Poverty, Job, State and the Future of the Capitalism. São Paulo, 1999.

[6] Abreu, M. A. The Urban Evolution of Rio de Janeiro. Rio de Janeiro, 1988. 